This is an electronic reprint of the original article. This reprint may differ from the original in pagination and typographic detail.

Author(s): Stosic, Jelena; Finni Juutinen, Taija

Title: Gastrocnemius tendon length and strain are different when assessed using straight or curved tendon model

Year: $\quad 2011$

Version:

Please cite the original version:

Stosic, J., \& Finni Juutinen, T. (2011). Gastrocnemius tendon length and strain are different when assessed using straight or curved tendon model. European Journal of Applied Physiology, 111(12), 3151-4. https://doi.org/10.1007/s00421-011-1929-9

All material supplied via JYX is protected by copyright and other intellectual property rights, and duplication or sale of all or part of any of the repository collections is not permitted, except that material may be duplicated by you for your research use or educational purposes in electronic or print form. You must obtain permission for any other use. Electronic or print copies may not be offered, whether for sale or otherwise to anyone who is not an authorised user. 


\section{Gastrocnemius tendon length and strain are different when assessed using straight or curved tendon model Stosic J \& Finni T}

In ankle plantarflexion the Achilles tendon is curved as compared to a neutral ankle joint angle. In magnetic resonance images this can be clearly visualized in relaxed condition (Fig. 1). The surface contour follows the tendon curvature and thus the kinematic measures from the surface of the skin can be considered to reflect also the tendon curvature in vivo.

While the Achilles tendon curvature is present in the relaxed condition, we have also done tests with dynamic settings within an MRI environment. Figure 2 shows an example from a pilot study by Finni et al. (2003a) where the tendon curvature is present during concentric actions. The plantarflexion was performed against a load provided by elastic bands. When the subjects performed repetitive actions a velocity-encoded cine phase-contrast sequence was used to acquire the images during the contraction-relaxation cycle (Finni et al. 2003b, Finni et al. 2008). As compared to the neutral or dorsiflexed condition, the tendon is curved and elongated when loaded (with about 30\% MVC) in plantarflexed position. These preliminary observations provided the paradigm for the present study.

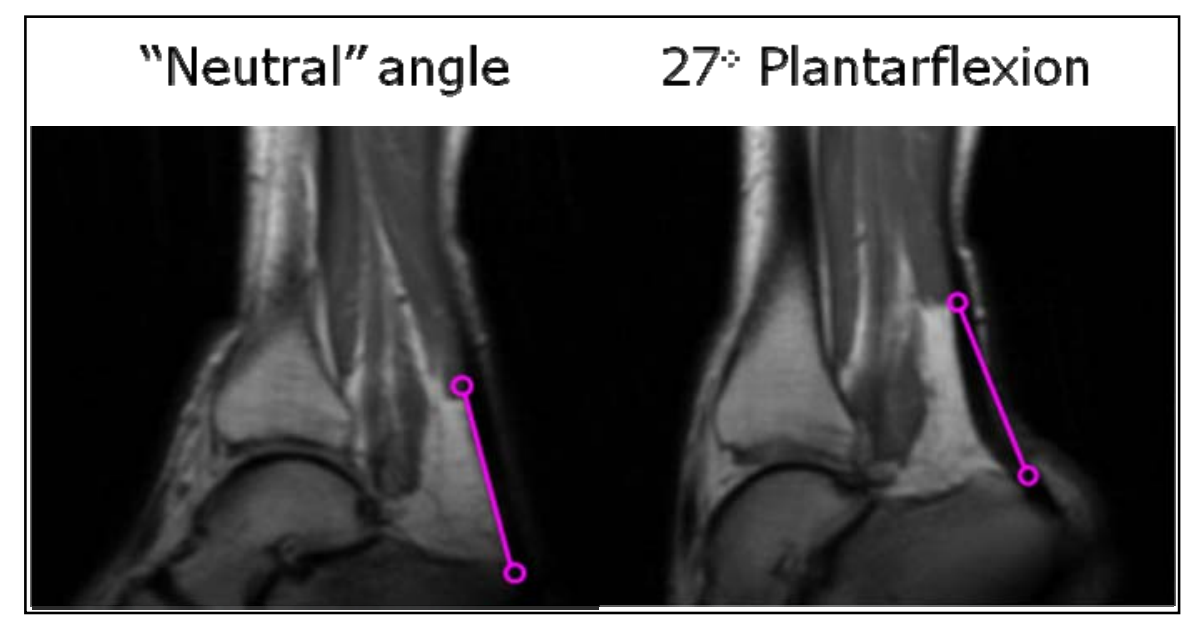

Figure 1. MR images from the ankle joint region in relaxed condition with ankle joint angle in neutral angle $\left(90^{\circ}\right)$ and in $27^{\circ}$ plantarflexion. The linear connector between Achilles tendon insertion at the soleus muscle and at the calcaneous allows visual estimation of the degree of curvature in the Achilles tendon which is the thick black structure beside the pink connector. 


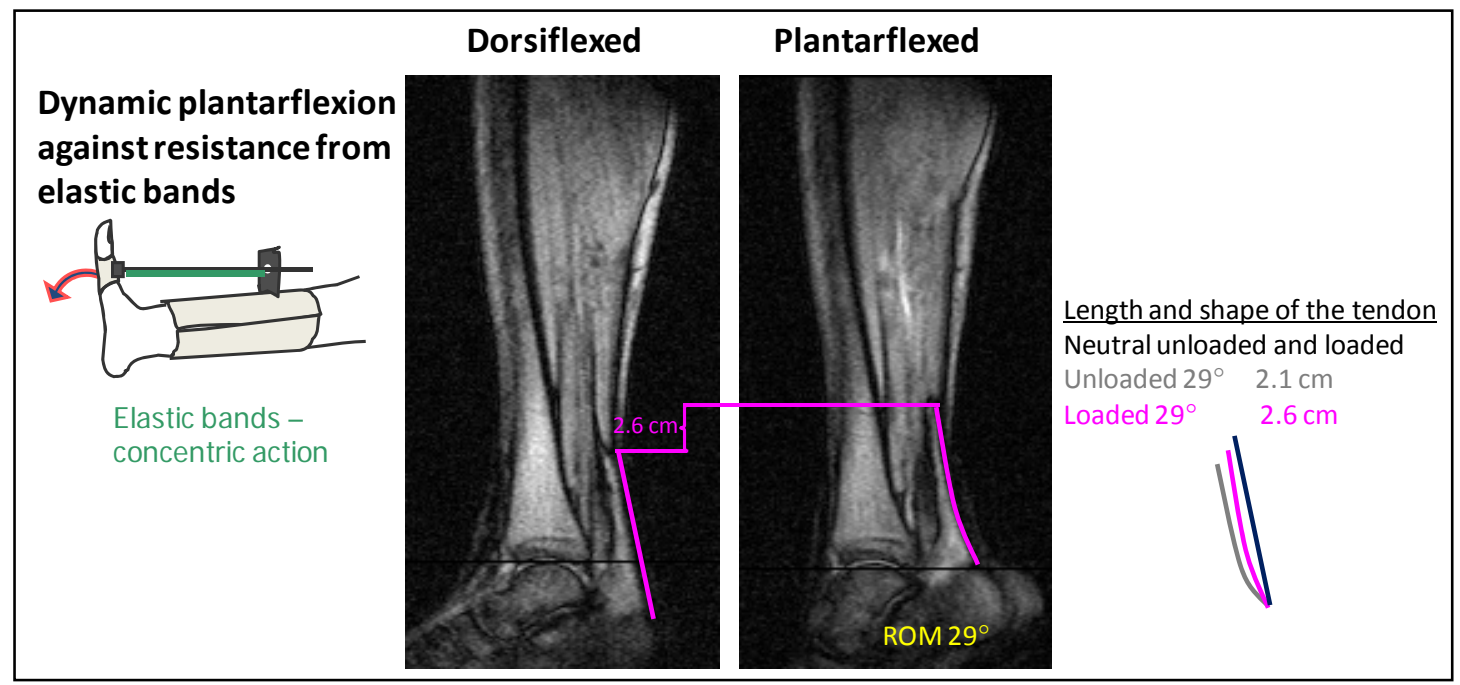

Figure 2. Data from pilot experiments that were presented at an IOC Congress by Finni et al. (2003a). Two MR images from dynamic contractions with range of motion (ROM) of $29^{\circ}$ showing that free Achilles tendon is curved and elongated in plantarflexed position during concentric action.

\section{References}

Finni T, Hodgson JA, Lai A, Edgerton VR, Sinha S (2003a) Triceps Surae MuscleTendon Function in Isometric and Passive Movements. Proceedings of the 7th IOC Olympic World Congress on Sport Sciences, Athens Oct 9-11.

Finni T, Hodgson JA, Lai A, Edgerton VR and Sinha S (2003b) Nonuniform strain of human soleus aponeurosis-tendon complex during submaximal voluntary contractions in vivo. Journal of Applied Physiology Aug, 95: 829 - 837.

Finni T, Havu M, Sinha S, Usenius J-P, Cheng S (2008) Mechanical behaviour of the quadriceps femoris muscle tendon unit during low load contractions. Journal of Applied Physiology 104: 1320-1328. 